\title{
Aspectos da tradução de textos de divulgação da ciência: um estudo de duas retextualizações para o português brasileiro e europeu
}

\author{
Aspects of translation of science popularization texts: \\ a study of two retextualizations into Brazilian \\ Portuguese and European Portuguese
}

Priscila Brasil Gonçalves Lacerda
UFMG
Adriana Silvina Pagano
UFMG

\begin{abstract}
This article discusses differences in the representation of a science popularization text based on an analysis of two retextualizations of $A$ brief history of time into Brazilian Portuguese (BP) and European Portuguese (EP). Drawing on Systemic Functional Grammar (HALLIDAY, 1994; HALLIDAY; MATTHIESSEN, 2004), particularly on categories pertaining to the textual and interpersonal metafunctions of language, two chapters of each translated text were analyzed with a view to mapping Theme and Subject and comparing the implications of choices in each retextualization for constructions of particular representations. Results point to minor differences as regards Theme choice, though substantial differences concerning Subject were found in the two texts. These differences, together with additions and misreadings, signal divergent views, which become significant for the science popularization genre due to its communicative function in society.
\end{abstract}




\section{Keywords}

Translation studies; Systemic-functional grammar; Theme; Subject; Science popularization.

\section{Resumo}

Este artigo apresenta uma discussão acerca da representação em texto de divulgação da ciência a partir da análise de duas retextualizações de $A$ brief history of time para o português brasileiro (PB) e para o português europeu (PE). Com base nas propostas da Gramática Sistêmico-Funcional (HALLIDAY, 1994; HALLIDAY e MATTHIESSEN, 2004), particularmente nas categorias pertinentes às metafunções textual e interpessoal da linguagem, foram analisados dois capítulos de cada texto traduzido, sendo observados os mapeamentos de Tema e de Sujeito e comparadas as implicações decorrentes das escolhas efetuadas em cada retextualização para a construção de representações particulares. Os resultados apontaram uma diferença pouco significativa no que diz respeito à escolha temática, ao passo que diferenças substanciais foram encontradas em ambos os textos no que concerne ao Sujeito. Essas diferenças, associadas a interpolações e equívocos, indicam a construção de representações diferentes nas traduções, o que é um fato significativo tendo em vista a função comunicativa do gênero divulgação da ciência na sociedade.

\section{Palavras-chave}

Estudos da Tradução; Gramática sistêmico-funcional; Tema; Sujeito; Divulgação da ciência. 


\section{Introdução}

egundo Munday (2001), as abordagens discursivas da tradução, sobretudo
na vertente orientada pela lingüística sistêmico-funcional hallidayana, têm
início na década de 1970 e consolidam-se nos anos noventa. Os estudos abordam a tradução (cf. PAGANO; VASCONCELLOS, 2005) mediante uma proposta de descrição da linguagem com base em metafunções, numa tentativa de, segundo palavras de M.A.K. Halliday, "buscar capturar a relação entre as formas internas da linguagem e seu uso em contextos de ação social"' (THIBAULT, 1987, p. 607). Os corpora de textos analisados contemplam preferencialmente pares de originais e textos traduzidos com predominância de alguns gêneros, tais como romances, contos, artigos jornalísticos e artigos acadêmicos. Embora menos freqüentes, estudos sobre diversas traduções de um mesmo texto original também têm sido desenvolvidos, tendo-se como foco os textos traduzidos e as representações que esses constroem em suas culturas receptoras. Entre os gêneros analisados, o gênero denominado divulgação ou popularização da ciência tem sido pouco explorado, fato que justifica sua investigação, dada sua relevância enquanto veículo de comunicação da comunidade acadêmica com a sociedade.

Neste trabalho, desenvolvemos um estudo exploratório do gênero de divulgação da ciência através de uma análise comparativa de duas retextualizações, ou seja, de duas traduções, uma em português brasileiro (PB) e outra em português europeu (PE), do original em língua inglesa: A brief history of time, de Stephen Hawking (1988). O estudo visa indagar, com base em categorias da lingüística sistêmico-funcional, em que medida representações diferentes são construídas em cada retextualização.

Na seção seguinte apresentamos um esboço da teoria que fundamenta a presente análise. Em seguida, expomos os objetivos que nortearam esta pesquisa e os procedimentos metodológicos, por meio dos quais obtivemos os dados de análise. Por fim, apresentamos esses dados e discutimo-los, apontando as questões de maior relevância. 


\section{Tema e sujeito na gramática sistêmico-funcional}

O presente estudo tem como fundamentação teórica a gramática sistêmico-funcional (HALLIDAY, 1994; HALLIDAY; MATTHIESSEN, 2004). Tal teoria contempla a linguagem considerando o sistema lingüístico enquanto constituído por redes de opções associadas às funções que a linguagem exerce e às demandas que fazemos a ela. Halliday, portanto, a fim de explicar o fenômeno lingüístico desenvolve uma teoria dos níveis de linguagem fundamentais, na qual ele analisa as manifestações léxico-gramaticais por meio de três metafunções: a ideacional, a textual e a interpessoal.

A metafunção ideacional diz respeito à relação entre a linguagem e o mundo natural em sentido lato, inclusive as relações construídas em nossa própria consciência (HALLIDAY, 1976, p.136). As orações, nesse caso, são consideradas como representações da realidade, das percepções sensíveis e inteligíveis. Sob o viés dessa metafunção, a oração é estruturada em Processos, Participantes e Circunstâncias, ou seja, os elementos que constituem o Sistema da Transitividade, o qual é centralizado nos processos e configura a oração enquanto representação (HALLIDAY, 1994, p. 52).

Já a metafunção interpessoal trata do universo social que norteia, principalmente, as relações entre o emissor e o receptor, os quais alternam seus papéis em uma interação verbal. A oração, segundo tal metafunção, é organizada em Modo e Resíduo. No primeiro, o Modo, encontram-se o Sujeito e o Finito, nos quais se manifesta a perspectiva adotada pelo emissor, perspectiva essa que implica um posicionamento atribuído ao receptor. Já no segundo, o Resíduo, estão o(s) Predicador(es), o(s) Complemento(s) e o(s) Adjunto(s). O Sistema de Modo, por sua vez, configura a oração como troca, intercâmbio de significações entre os interlocutores.

Por fim, a metafunção textual refere-se ao aspecto verbal, considera a oração como mensagem em correspondência com o fluxo de informações do texto no qual ela se encontra. A oração, nesse caso, é estruturada em Tema e Rema (HALLIDAY, 1994, p. 37).

Ressaltamos que, embora tais sistemas funcionais relacionem-se a aspectos diferenciados do uso que fazemos da linguagem, eles atuam simultaneamente na organização da oração (HALLIDAY, 1976, p. 137). Todavia, uma análise realizada sob o respaldo de determinada metafunção leva em conta a correspondente organização estrutural das orações e a que propósito tais orações servem. Assim, 
se analisássemos a oração "O cientista sorriu com superioridade [...]" (HAWKING, 2000) ${ }^{1}$ de acordo com cada uma das metafunções, iríamos nos basear nas classificações apresentadas no Quadro I.

\section{QUADRO I}

Exemplo de classificação dos elementos da oração segundo as categorias propostas por metafunção

\begin{tabular}{|c|c|c|c|c|}
\hline METAFUNÇÕES & $O$ cientista & sorriu & \multicolumn{2}{|c|}{ com superioridade [...] } \\
\hline Ideacional & $\begin{array}{l}\text { Participante: } \\
\text { Comportante }\end{array}$ & $\begin{array}{c}\text { Processo: } \\
\text { Comportamental }\end{array}$ & \multicolumn{2}{|c|}{$\begin{array}{c}\text { Circunstância: } \\
\text { Modo }\end{array}$} \\
\hline \multirow[t]{2}{*}{ Interpessoal } & \multicolumn{2}{|c|}{ Modo } & \multicolumn{2}{|c|}{ Resíduo } \\
\hline & Sujeito & Finito & Predicador & Adjunto \\
\hline Textual & $\begin{array}{c}\text { Tema: } \\
\text { ideacional } \\
\text { participante }\end{array}$ & & \multicolumn{2}{|c|}{ Rema } \\
\hline
\end{tabular}

Nossa pesquisa concentra-se, mais especificamente, nas categorias Tema e Sujeito previstas pelas metafunções textual e interpessoal, respectivamente. Em vista disso, tais categorias serão mais detalhadamente explicitadas a seguir.

"O Tema é o elemento que serve como ponto de partida da mensagem: é o que determina e orienta a oração dentro de seu contexto" (HALLIDAY; MATTHIESSEN, 2004, p. 64). Em português, o elemento temático ocupa a posição inicial da oração, assim como em inglês. O Tema deve conter, necessariamente, um e somente um elemento da estrutura de transitividade, ou seja, a sua dimensão estende-se até, e inclui, o primeiro componente ideacional da oração. "Todo o resto da oração é basicamente chamado de Rema.” (THOMPSON, 2002, p. 119).

O elemento que exerce uma função no Sistema da Transitividade, em uma abordagem textual, é classificado como Tema topical ou experiencial. ${ }^{2}$ Tendo em vista que o Tema é delimitado pelo primeiro elemento ideacional da oração, o qual é imprescindível, temos a presença de um Tema dessa natureza em qualquer oração.

\section{Exemplo 1}

As nossas ideias actuais sobre o movimento dos corpos vêm dos tempos de Galileu e de Newton. (HAWKING, 2004, cap.2, §1) 
Ao tomarmos o Exemplo 1, observamos em destaque o Tema da oração, o qual é classificado como Tema topical participante, pois é realizado por um grupo nominal que funciona como Participante do Processo "vêm". Vejamos no Quadro 2 os tipos de Tema topical que consideramos na anotação do corpus.

QUADRO2

Tipos de Tema topical

\begin{tabular}{|c|c|c|c|}
\hline \multirow[t]{2}{*}{ Tema topical } & $\begin{array}{l}\text { participante } \\
\text { processo } \\
\text { circunstância } \\
\text { oracional }\end{array}$ & Tema topical & $\begin{array}{l}\text { equativo } \\
\text { predicado } \\
\text { comentário } \\
\text { preposto }\end{array}$ \\
\hline & elíptico & Tema tópico & \\
\hline
\end{tabular}

Lembramos que, como afirmam Gouveia \& Barbara (2000, p. 18), o ponto de partida da mensagem pode consistir em um elemento não lexicalizado. Tal fato mostra-se recorrente em português com a não lexicalização do Participante (correspondente ao sujeito gramatical da oração), sendo este identificado pela desinência de número e pessoa do Processo (finito). Assim, a elipse do Participante (sujeito) classificamos como Tema tópico.

É importante esclarecer a diferença existente entre o Tema tópico e o Tema topical elíptico. A categoria vazia que representa o Tema tópico, nos casos de elipse de pronome ou grupo nominal que realiza um Participante, aponta para um referente, seja por anáfora ou por dêixis; o que podemos comprovar pelo fato de o Processo (finito) apresentar concordância com a pro-forma que ocuparia o lugar vazio. Então, temos um recurso coesivo de ordem semântica, a saber, uma Referência (HALLIDAY, 1994) por substituição; nesse caso, a substituição está sendo realizada por uma categoria vazia (BARBARA; GOUVEIA, 2001, p. 9). O Tema topical elíptico, por sua vez, é representado por uma elipse que configura-se como artifício coesivo estrutural. Observemos as orações abaixo.

Exemplo 2

(a) Nele, Newton não apenas desenvolve a teoria de como os corpos se movem no espaço e no tempo, mas também [TEMA TÓPICO] fornece a complexa matemática para analisar tais movimentos. (cap.1, §7) 
(b) [...] Ptolomeu teve que estabelecer o pressuposto de que a Lua seguia uma trajetória tal que em algumas épocas a levava duas vezes mais perto da Terra do que em outras. [TEMA TOPICAL ELÍPTICO] O que significava que a Lua deveria, em algumas ocasiões, parecer duas vezes maior do que em outras! (cap.1, §5) (HAWKING, 2000)

No Exemplo 2(a), reconhecemos um Tema tópico representado pelo vazio que aponta para o participante "Newton", ou seja, há um resquício semântico desse participante na categoria vazia. Já em 2(b), verificamos um Tema topical elíptico resultante de uma organização estrutural peculiar em que a oração dependente se apresenta enquanto componente único de um período, estando em elipse a oração principal à qual ela se relaciona.

Retomando o Exemplo 1 (As nossas ideias actuais sobre o movimento dos corpos vêm dos tempos de Galileu e de Newton.), notamos que o Tema da oração comporta uma única unidade estrutural, i.e., não há nenhum elemento que preceda o Tema topical, portanto estamos diante de um Tema simples.

Vimos na definição que o Tema "determina e orienta a oração dentro de seu contexto"; ele estabelece o contexto para a interpretação da parte da mensagem encontrada no Rema. Por vezes, o exercício dessa função torna-se mais complexo, ou seja, o emissor introduz, antes do Tema topical, um conectivo estabelecendo uma relação com o que vem anteriormente; nesses casos, temos um Tema textual. Há também ocorrências em que o emissor insere antes do Tema topical um elemento que expressa uma avaliação, uma perspectiva sua acerca da mensagem veiculada pela oração; nessas situações, encontramos um Tema interpessoal. Vejamos as orações seguintes.

Exemplo 3

(a) Assim, a força total entre A e B será duas vezes a força original. (cap.2, §3)

(b) Só nessa altura os acontecimentos na Terra ficariam no cone da luz do futuro do acontecimento da morte do Sol. (cap.2, §21) (HAWKING, 2004)

Em 3(a), "Assim" é classificado como Tema textual e "Só", em destaque no exemplo 3(b), é classificado como Tema interpessoal. Tendo em vista que 
nenhum desses Temas apresenta elementos da estrutura da transitividade (Processo, Participantes ou Circunstâncias), o elemento seguinte, primeiro elemento da estrutura da transitividade, é o Tema topical da oração. Desse modo, "a força total entre Ae B" (3(a)) é um Tema topical participante, e "nessa altura" (3(b)) consiste em um Tema topical circunstância. Em ambos os casos, temos um Tema múltiplo, composto por um Tema textual ou interpessoal seguido de um Tema topical.

Uma outra classificação que atribuímos ao Tema relaciona-se ao modo oracional. As orações declarativas e as interrogativas polares, tipicamente apresentam o sujeito gramatical ${ }^{3}$ em posição inicial. Já as orações interrogativas Qu- são comumente iniciadas pelo elemento interrogativo; ao passo que as imperativas apresentam com mais freqüência um Processo em posição temática. Assim, quando o Tema de uma oração corresponde ao elemento tipicamente colocado em posição inicial, segundo o modo dessa oração, temos um Tema não marcado. Contudo, se um elemento diverso ocupa a posição temática, estamos em face de um Tema marcado. Notamos que esse último demonstra maior expressividade do emissor, uma vez que resulta de uma escolha motivada. Observemos o exemplo logo abaixo, no qual encontramos um Tema marcado, "Chegará", já que temos um Processo em posição inicial, quando o esperado seria um Participante, pois estamos diante de uma oração interrogativa polar.

Exemplo 4

Chegará ele a um termo? (HAWKING, 2000, cap.1, §2)

Passemos agora à explicitação da categoria que tomamos da Metafunção interpessoal da linguagem, o Sujeito. De acordo com Halliday (1994) e Halliday e Matthiessen (2004), podemos defini-lo como uma categoria semântica que fornece a informação em relação à qual uma proposição pode ser afirmada ou negada. Exemplo 5

O modelo de Ptolomeu estabelecia um sistema razoavelmente preciso de prever as posições dos corpos celestes no firmamento. (HAWKING, 2000, cap.1, §2)

Seguindo a teoria sistêmico-funcional, é no âmbito do Sujeito que reside a validade da informação. Desse modo, reivindicamos que a asserção presente no Exemplo 5 seja válida tendo em vista, primeiramente, a entidade a qual ela se refere, i.e, "O modelo de Ptolomeu", que exerce a função de Sujeito nessa oração. 
Embora aqui a definição de Sujeito respalde-se em um princípio semântico, nós localizamos tal categoria por meio de critérios morfológicos. Dessa maneira, apontamos como Sujeito o elemento que apresente concordância em número e pessoa com o Finito.

Desenvolvemos a presente análise considerando as funções Tema, pertinente em uma perspectiva da oração como mensagem, e Sujeito, reconhecido na oração como proposição. Valemo-nos, portanto, das implicações que subjazem a atribuição dessas categorias, as quais foram apontadas por Halliday e seus discípulos.

\section{Objetivos do estudo}

Partimos de Gouveia \& Barbara (2003) que analisaram comparativamente a organização temática de duas retextualizações do gênero romance para o português brasileiro (PB) e europeu (PE). Esses autores encontraram diferenças entre os textos traduzidos que denominaram "estilísticas", i.e., que não produzem diferenças significativas de representação.

Pretendemos, neste trabalho, explicitar as diferenças temáticas existentes entre duas retextualizações, também para o PB e PE; bem como tencionamos apontar as diferenças decorrentes das escolhas de Sujeito. Vale dizer que não perdemos de vista as especificidades dos textos que constituem o nosso corpus; em outras palavras, objetivamos verificar, por meio da observação dessas categorias, se duas retextualizações do gênero divulgação da ciência também apresentariam diferenças meramente estilísticas ou não, e até que ponto as diferenças contribuiriam para gerar representações diferentes.

Ainda tivemos como objetivo realizar uma aplicação da teoria desenvolvida na gramática sistêmico-funcional à análise de textos em língua portuguesa, já que tal teoria, não obstante tenha sido desenvolvida com base na língua inglesa, consiste em uma reflexão abrangente acerca da linguagem.

\section{Procedimentos metodológicos}

Primeiramente, preparamos o corpus a ser analisado. Foi efetuada a digitalização dos capítulos 1 e 2 dos textos traduzidos ou retextualizações: Uma breve história do tempo, traduzido por Maria Helena Torres (2000) para o PB, e Breve história do tempo, tradução de Maria Alice da Costa (2004) para o PE. Vale lembrar que o rastreamento de quaisquer elementos nos textos torna-se mais 
fácil se esses se encontram em formato eletrônico, o que justifica o trabalho com um corpus digitalizado.

A próxima etapa consistiu na correção dos erros advindos das imperfeições do processo de digitalização. Os reparos são feitos a fim de que as versões em formato eletrônico, a serem inseridas no banco de dados do CORDIALL (Corpus Discursivo para Análises Lingüísticas e Literárias), ${ }^{4}$ ao qual se vincula esta pesquisa, estejam tal qual a sua forma impressa, favorecendo, assim, a fidedignidade dos dados extraídos dos textos.

Em seguida, foi realizada a anotação do corpus. Marcamos as categorias Tema e Sujeito, segundo a proposta da gramática sistêmico-funcional. Como se pode observar no Exemplo 6, destacamos os primeiros sublinhando-os, e inserimos a classificação temática entre colchetes [ ]. Já os últimos, os Sujeitos, foram destacados em negrito e itálico.

Exemplo 6

Um dia [TS.M.C] essas respostas poderão parecer tão óbvias para nós como o facto de a Terra girar em volta do Sol; (HAWKING, 2004, cap.1, §2)

As classificações dos Temas foram apontadas entre colchetes por meio de suas iniciais. Assim, no Exemplo 6, temos "Um dia" como [TS.] = Tema simples, $[\mathrm{M}$.$] = Marcado, e [C] = Circunstância. O Sujeito "essas respostas",$ como foi dito acima, encontra-se sinalizado em negrito e itálico.

O último passo consistiu no alinhamento dos textos em parágrafos (vejamos o Exemplo 7), o que permitiu uma observação minuciosa das diferenças existentes entre as retextualizações. Tal procedimento justifica a utilização de fontes sublinhadas ou em negrito e itálico para destacar elementos nos textos.

\section{Exemplo 7}

O modelo de Copérnico [TS.nM.P] libertou-se das esferas celestes de Ptolomeu e, com elas, da idéia de que o universo tenha um limite natural. Uma vez que as estrelas fixas parecem não mudar suas posições independente da rotação através do céu, provocada pelo movimento rotativo da Terra em torno de seu eixo, [TS.M.O] é natural supor que <as estrelas> sejam corpos semelhantes ao Sol, só que muito mais distantes. (HAWKING, 2000, cap.1, §8) 
O modelo de Copérnico [TS.NM.P] fez desaparecer as esferas celestes de Ptolemeu e, com elas, a ideia de que o universo apresentava uma fronteira natural. Uma vez que as $<<$ fixas $>>$ não pareciam alterar a sua posição, exceptuando o movimento aparente de rotação, que tem origem no movimento da Terra em torno do seu eixo em sentido contrário, [TS.M.O] tornou-se natural supor que <as estrelas $>$, assimiláveis ao nosso Sol, se encontravam muito mais longe. (HAWKING, 2004, cap.1, §8)

Finalizados os procedimentos metodológicos, passamos à análise dos dados obtidos.

\section{Resultados alcançados e discussão}

Os resultados apresentados aqui constituem uma análise dos dados extraídos dos capítulos 1 e 2 como um todo, pois não objetivamos realizar uma comparação entre esses capítulos considerados separadamente, i.e., não pretendemos apreender as diferenças que eles apresentam entre si. Antes, procuramos evidenciar as diferenças existentes entre as duas retextualizações, sendo uma brasileira e outra portuguesa, tendo em vista que elas foram motivadas por um mesmo texto fonte.

Propomo-nos a verificar se há diferenças temáticas e de Sujeito entre os textos-alvo e em que medida tais especificidades contribuem para a representação construída em cada retextualização. Uma vez que a nossa análise possui como foco principal questões de ordem discursiva, explicitamos adiante as diferenças mais representativas, sem nos atermos a aspectos quantitativos.

Observamos a presença de Temas topicais participante no texto em PB enquanto temos Temas tópico em $\mathrm{PE}$, oque se deve à maior ocorrência de participantes lexicalizados no primeiro, ao passo que, no segundo, há um número considerável de participantes não expressos lexicalmente, ou seja, que são indicados por uma categoria vazia. Tal observação verifica-se também em Gouveia \& Barbara (2003).

Exemplo 8

(a) $\mathrm{PB} \rightarrow$ Tema topical participante

Ele apontava que a civilização está progredindo e que nós nos lembramos quem realizou este feito ou desenvolveu aquela técnica. (HAWKING, 2000, cap.1, §14) 
(b) PE $\rightarrow$ Tema tópico

[Santo Agostinho] ${ }^{5}$ Chamou a atenção para o facto de a civilização estar a progredir e de [nós] nos lembrarmos daqueles que realizaram feitos heróicos e dos que inventaram novas técnicas. (HAWKING, 2004, cap.1, §14)

Percebemos, ainda, a ocorrência de Temas topicais processo em PB onde encontramos Temas tópico em PE. Tal diferença decorre da presença de participantes indeterminados em PB enquanto o Participante "nós" é utilizado em $\mathrm{PE}$, mesmo que não realizado ou apresentado como categoria vazia.

Exemplo 9

(a) $\mathrm{PB} \rightarrow$ Tema topical processo.

Por isso divide-se o problema em diversas partes [...] (HAWKING, 2000, cap.1, §23)

(b) $\mathrm{PB} \rightarrow$ Tema tópico

Em vez disso, dividimos o problema em partes [...] (HAWKING, 2004, cap.1, §23)

Nesse caso, em certa medida, observamos uma diversidade de representação, pois, enquanto em $\mathrm{PB}$ o foco incide sobre o Processo, já que o Participante é indeterminado, em PE temos um Participante - "nós" - implícito, no qual o emissor se inclui. Todavia, a diferença de representação é motivada antes pela diferença de Sujeito do que pela diferença temática que lhe é concomitante.

Portanto, notamos que as diferenças temáticas mais recorrentes, as quais foram exemplificadas nos exemplos 8 e 9 , exprimem somente peculiaridades das referidas variantes da língua portuguesa ou, como vimos no Exemplo 9, motivam apenas tênues diferenças de representação. Contudo, ao analisarmos os Sujeitos, encontramos algumas diferenças, as quais manifestam mudanças em nível de significado ideacional, ou seja, apontam para divergências de representação. Comprovamos isso no exemplo logo a seguir.

Exemplo 10

$\mathrm{PB} \rightarrow$ [Galileu] deixou rolarem bolas de pesos diferentes numa inclinação suave. A situação é semelhante àquela dos corpos pesados caindo verticalmente, mas é de mais fácil observação, porque $\underline{a s}$ 
velocidades desenvolvidas são menores. A mensuração de Galileu indicava que todos os corpos aumentavam sua velocidade à mesma razão, independente do peso de cada um. Por exemplo, se lançamos uma bola sobre uma ladeira que se incline um metro em cada dez metros de sua extensão, a bola rolará, após um segundo, numa velocidade de aproximadamente um metro por segundo, após dois segundos, dois metros por segundo, e assim por diante, independente de seu peso. (HAWKING, 2000, cap.2, §2)

$\mathrm{PE} \rightarrow$ [Galileu] fez rolar bolas de pesos diferentes pelo suave declive de um plano inclinado. A situação é semelhante à de corpos pesados que caem verticalmente, mas mais fácil de observar, porque Los corpos pesados $]$ se movimentam com velocidades menores. As medições de Galileu indicavam que a velocidade de cada corpo aumentava na mesma proporção, qualquer que fosse o seu peso. Por exemplo, se deixarmos rolar uma bola por uma encosta que desce 1 metro por cada 10 metros de caminho andado, veremos que a bola se move com uma velocidade de cerca de 1 metro por segundo após um segundo, 2 metros por segundo após dois segundos, etc., por mais pesada que seja. (HAWKING, 2004, cap.2, §2)

Por vezes, como já foi demonstrado, tais diferenças de Sujeito ocorrem concomitantemente a diferenças de Tema. Observando os Sujeitos (em negrito e itálico) encontrados nos fragmentos do Exemplo 11 a seguir, notamos que, em PB, o foco inicial incide sobre "os gregos" e logo depois sobre "a estrela polar". Nas proposições seguintes, porém, ele é transferido para "um observador que aí se encontre" e "alguém que esteja no equador". Já em PE, temos na primeira proposição "Os gregos" como Sujeito, e depois encontramos "a Estrela polar" conservando a função de Sujeito nas demais proposições. É evidente, nesse caso, que há diferenças entre as versões brasileira e portuguesa no que concerne à entidade em relação à qual as informações são apresentadas.

Observamos ainda que, em PB, há uma coincidência entre o Sujeito e o elemento Tema topical participante da primeira oração adversativa, ao passo que, em PE, temos na oração equivalente um Tema topical circunstância que, portanto, não é representado pelo elemento Sujeito, o qual, em todo caso, é diverso daquele encontrado na tradução para o PB. Ao verificarmos a segunda oração adversativa, também encontramos diferenças de Sujeito e de Tema. Se, em PB, temos como 
Sujeito não lexicalizado "a medida exata de um estádio", que representa a categoria vazia que exerce a função de Tema tópico, em PE, encontramos a indeterminação do elemento Sujeito e o Tema processo "pensa-se".

Exemplo 11

$\mathrm{PB} \rightarrow[\ldots]$ os gregos sabiam, por suas experiências de viagens, que a estrela polar parecia mais baixa no céu quando vista do sul do que se observada de regiões mais ao norte. (Uma vez que a estrela polar fica sobre o Pólo Norte, um observador que aí se encontre perceberá a estrela precisamente sobre si; mas alguém que esteja no equador a observará exatamente na linha do horizonte.) Da_diferença na posição aparente da estrela polar no Egito e na Grécia, Aristóteles pôde fazer uma estimativa de que a distância em volta da Terra era de 400 mil estádios. Não se conhece a medida exata de um estádio, mas [a medida exata de um estádio] deve ser muito próxima de 180 m, o que tornaria a estimativa de Aristóteles duas vezes maior do que a distância atualmente aceita. (HAWKING, 2000, cap.1, §3)

$\mathrm{PE} \rightarrow[\ldots]$ os Gregos sabiam, das suas viagens, que a Estrela Polar surgia menos alta no céu quando era observada mais a sul das regiões onde se encontra mais alta. Uma vez que $\boldsymbol{a}$ Estrela Polar se encontra no zênite do Pólo Norte, [a Estrela Polar] parece estar directamente por cima de um observador no pólo boreal, mas para um observador no equador ela encontra-se na direcção do horizonte:

A partir da diferença da posição aparente da Estrela Polar no Egipto e na Grécia, Aristóteles estimou o perímetro da Terra em 400000 estádios. Não se sabe exactamente o valor da medida de comprimento que os Gregos designavam por estádio, mas pensa-se que [a medida de comprimento que os gregos designavam estádio] seria de 180 metros, o que equivale a dizer que Aristóteles calculou cerca de duas vezes o valor real do perímetro da Terra. (HAWKING, 2004, cap.1, §3)

Novamente percebemos, no Exemplo 12 adiante, uma diferença de Sujeito simultâneaà divergência temática. "Newton" éo elemento que funciona como Sujeito da proposição em $\mathrm{PB}$, ao passo que essa categoria é representada pelo sintagma "Muitas pessoas" em PE. Por conseguinte, temos que a validade das proposições apresentadas nesse exemplo converge para entidades diferentes: o observador em $\mathrm{PB}$ e a estrela polar em $\mathrm{PE}$, o que já indica a construção de representações diferentes. 
No mesmo exemplo, ao observarmos o Tema, notamos que, em PB, temos uma circunstância indicando causalidade como ponto de partida da mensagem, ou seja, estamos diante de um Tema topical circunstância, marcado; assim, o restante da oração será interpretado tendo em vista a causa do evento. Já na oração em PE, o Sujeito "Muitas pessoas" encontra-se também em posição temática, o que modifica consideravelmente a perspectiva interpretativa. Tal modificação é endossada pelo fato de "crença irracional" representar um Participante em PE, ao passo que, em PB, se configura como um componente circunstancial. Apreendemos, desse modo, que a divergência de Sujeito associada à diferença quanto ao Tema revela-se com impacto na construção de representações diferenciadas nos textos traduzidos.

Exemplo 12

$\mathrm{PB} \rightarrow$ Devido à sua crença irracional, Newton foi severamente criticado por muitas pessoas [...] (HAWKING, 2000, cap.2, §7)

$\mathrm{PE} \rightarrow$ Muitas pessoas criticaram severamente a sua crença irracional,[...] (HAWKING, 2004, cap.2, §7)

Considerando que o Sujeito exerce um papel primordial na relação que está sendo estabelecida, podemos afirmar que ele detém o foco da proposição. Destarte, sendo o Sujeito o ponto de sustentação do argumento proposicional (HALLIDAY; MATTHIESSEN, 2004, p. 118), a divergência no que concerne a esse ponto de sustentação implica diferenças de foco (centralidade) das proposições gerando, por conseguinte, uma representações diferente.

Ao examinarmos o corpus, encontramos ainda diferenças relativas ao conteúdo proposicional resultantes de interpolações feitas pelo tradutor no texto em PE. Vejamos o exemplo a seguir.

\section{Exemplo 13}

PB $\rightarrow$ Por exemplo, a teoria de Aristóteles de que tudo foi originado a partir dos quatro elementos, terra, ar, fogo e água, era suficientemente simples para qualificar, porém não fazia qualquer previsão definida. (HAWKING, 2000, cap.1, §19)

$\mathrm{PE} \rightarrow$ Por exemplo, Aristóteles acreditava na teoria, que é de Empédocles, segundo a qual todas as coisas eram compostas por quatro elementos - terra, ar, fogo e água. Era suficientemente simples 
para valer como tal, embora apresentasse um conteúdo previsível pobre. (HAWKING, 2004, cap.1, §19)

Na retextualização para o $\mathrm{PE}$, observamos um trecho para o qual não há correspondente em PB. Se as divergências de Sujeito e Tema, tomadas na esfera oracional, são constitutivas de uma diferença de representação no âmbito textual, i.e., se projetamos o seu escopo para o texto considerado como todo; a presença do referido trecho em PE (destacado em negrito no Exemplo 13), configura-se, por si, como uma divergência de representação em um nível mais amplo, ou seja, no nível textual.

Algo semelhante ocorre no Exemplo 14, em que podemos encontrar uma informação (destacada em negrito) que não está presente no texto em PB.

Exemplo 14

$\mathrm{PB} \rightarrow$ Se lançamos dois corpos sem muita resistência ao ar, como dois pesos de chumbo diferentes, eles caem na mesma velocidade. (HAWKING, 2000, cap.2, §2)

$\mathrm{PE} \rightarrow$ Se deixarmos cair dois corpos que sofram pouca resistência por parte do ar, por exemplo dois pesos de chumbo diferentes, o tempo de queda será o mesmo. Na Lua, onde não há ar que oponha resistência aos corpos que caem, o astronauta David R. Scott fez experiências com penas e pesos de chumbo e verificou que estes atingiam o solo ao mesmo tempo. (HAWKING, 2004, cap.2, §2)

Notamos, na versão portuguesa, a presença de retificações (como aquela apontada no Exemplo 13), ou ainda de acréscimos de informação (vide Exemplo 14), os quais, naturalmente, produzem uma representação diferente na versão portuguesa se comparada à brasileira. ${ }^{6}$ Foi encontrado, ainda, um caso em que a divergência de representação resulta de um equívoco presente na retextualização para o PB. Tal fato revela-se digno de nota, uma vez que o texto de divulgação da ciência propõe-se a promover o acesso do público leigo a um conhecimento científico que seja fidedigno.

Exemplo 15

$\mathrm{PB} \rightarrow$ (O tempo gasto é, ao fim e ao cabo, apenas a velocidade da luz - sobre a qual os observadores concordam - multiplicada pela distância que a luz percorreu - sobre a qual eles não concordam.) (HAWKING, 2000, cap.2, §14) 
$\mathrm{PE} \rightarrow \mathrm{O}$ tempo gasto é apenas a distância percorrida pela luz - com o que os observadores não concordam - dividida pela velocidade valor comum aos observadores. (HAWKING, 2004, cap.2, §14)

No exemplo 15, a retextualização brasileira difere significativamente da retextualização portuguesa. Ao recorrermos a HAWKING (1988), o texto original, encontramos a seguinte textualização:

(The time taken is the distance the light has traveled - which the observers do not agree on - divided by the light's speed - which they do agree on.)

Observamos, então, que a representação do texto de Hawking coincide com aquela proposta pela retextualização portuguesa.

Verificamos, dessa forma, que as diferenças de Tema, embora manifestem diferenças no âmbito da textura, não repercutem significativamente na produção de representações diversas, o que vai ao encontro de Gouveia \& Barbara (2003), que encontraram diferenças meramente "estilísticas" na análise que fizeram da organização temática de dois romances traduzidos. Percebemos, porém, que isso não ocorre se considerarmos o Sujeito, uma vez que a observação dessa categoria revelou diferenças de representação entre as retextualizações. Notamos, ainda, que outras questões como interferências do tradutor para o PE e equívocos advindos do processo de tradução para o PB também contribuíram para a construção de representações distintas.

\section{Considerações finais}

Este trabalho consistiu em um estudo de caso que visou contribuir para o mapeamento das características discursivas de retextualizações do gênero divulgação da ciência apresentando uma análise comparativa baseada nas categorias Tema e Sujeito, segundo as encontramos na gramática sistêmico-funcional.

Ao realizarmos uma comparação entre duas retextualizações de um mesmo texto fonte do referido gênero, observamos que, se, por um lado, as diferenças de Sujeito revelaram-se bastante expressivas no que diz respeito à constituição de diferenças de representação, por outro lado, as diferenças temáticas mostraram-se pouco relevantes nesse sentido. Podemos ressaltar, 
também, que tais diferenças figuram-se ainda mais significativas se considerarmos o propósito dos textos do gênero divulgação da ciência, que sustentam um compromisso com o valor de verdade diverso, a saber, mais acentuado, daquele mantido por textos do gênero romance.

\section{Notas}

${ }^{1}$ Todos os exemplos que serão apresentados, tanto nesta seção quanto nas seguintes, foram extraídos de nosso corpus de análise. A referência "HAWKING, 2000" corresponde à versão do Brasil, ao passo que a referência "HAWKING, 2004" remete à versão de Portugal.

${ }^{2}$ Podemos nomeá-lo também como Tema ideacional.

${ }^{3}$ Referimo-nos aqui ao sujeito categorizado pela gramática tradicional, a qual define o elemento que exerce tal função sintática como "o termo da oração que denota a pessoa ou coisa de que afirmamos ou negamos uma ação, estado ou qualidade" (BECHARA, 1976, p. 199). Mais adiante trataremos da categoria Sujeito segundo a gramática sistêmico-funcional.

${ }^{4} \mathrm{O}$ grupo CORDIALL está na Faculdade de Letras da UFMG.

${ }^{5}$ Nos exemplos, os elementos que estão entre colchetes não se encontram lexicalizados no corpus. Aqui explicitamos as categorias vazias para melhor compreensão das sentenças.

${ }^{6}$ Em sua resenha da tradução portuguesa do livro A brief history of time, Carlos Fiolhais, Professor de Física da Universidade de Coimbra, apresenta uma crítica às intervenções do revisor que, segundo suas palavras, "abusou um pouco das prerrogativas e anotou onde a anotação não era imperiosa". O professor também faz uma crítica ao título dado à versão portuguesa, Breve história do tempo, em que não se manteve o artigo indefinido encontrado no título original, como foi feito na tradução brasileira editada pela Rocco. Ele ressalta que "o 'uma' não é aqui [no título] redundante, pois Hawking conta-nos a sua história que é 'uma' das histórias possíveis". Contudo, ainda segundo Carlos Fiolhais, não obstante a versão brasileira tenha sido mais apropriada com o título Uma breve história do tempo, esta, "do ponto de vista da terminologia técnica, [está] muito pior que a portuguesa". A referida resenha foi encontrada no sítio http://nautilus.fis.uc.pt/softc/Read_c/ gradiva/r2027.htm, consultado em 15 de maio de 2006. 


\section{Referências}

BARBARA, L.; GOUVEIA, C. A. M. It is not there, but is cohesive: the case of pronominal ellipsis of subject in Portuguese. In: $13^{\mathrm{TH}}$ EURO- INTERNATIONAL SYSTEMIC FUNCTIONAL LINGUISTICS WORKSHOP, 2001, University of Brest, 2001. Direct Paper 46. São Paulo: PUCSP, 2001.

BECHARA, E. Moderna gramática portuguesa. 20. ed. São Paulo: Companhia Editora Nacional, 1976. p. 199.

GOUVEIA, C. A. M.; BARBARA, L. Tema e estrutura temática em PE e PB: um estudo contrastivo das traduções portuguesa e brasileira de um original inglês. In: $3^{\circ} \mathrm{COLÓQUIO} \mathrm{PORTUGUÊS} \mathrm{EUROPEU} \mathrm{E} \mathrm{PORTUGUÊS} \mathrm{BRASILEIRO-Unidade}$ e Diversidade na Passagem do Milênio, 2002, Faculdade de Letras, Universidade de Lisboa. Direct Papers 48. PUC-SP e University of Liverpool, 2003. Disponível em: $<$ http://www2.lael.pucsp.br/direct/DirectPapers48.pdf>. Acesso em: 15 maio 2006.

. Marked or unmarked that is NOT the question, the question is: Where's the theme? In: $12^{\mathrm{TH}}$ EURO-INTERNATIONAL SYSTEMIC FUNTIONAL LINGUISTICS WORKSHOP, 2000, University of Glasgow. Direct Paper 45. São Paulo: PUCSP, 2000. Disponível em: <http://www2.lael.pucsp.br/direct/ DirectPapers45.pdf>. Acesso em: 15 maio 2006.

HALLIDAY, M. A. K.; MATTHIESSEN, C. An introduction to functional grammar. 3. ed. London: Edward Arnold, 2004.

HALLIDAY, M. A. K. An Introduction to Functional Grammar. 2. ed. London: Edward Arnold, 1994.

Estrutura e função da linguagem. Trad. Jesus Antônio Durigan. In: LYONS, J. (Org.). Novos horizontes em lingüística. São Paulo: Cultrix/USP, 1976. p. 134-160.

HAWKING, S. Breve história do tempo. 6. ed. Trad. Maria Alice Gomes da Costa. Lisboa: Gradiva, 2004. p.9-47.

. Uma breve história do tempo. Trad. Maria Helena Torres. Rio de Janeiro: Rocco, 2000. p. 17-60.

HAWKING, S. A brief history of time. New York: Bantam, 1988.

MUNDAY, J. Introducing translation studies; theories and applications. London \& New York: Routledge, 2001.

PAGANO, A.; VASCONCELLOS, M. L. Explorando interfaces: estudos da tradução, lingüística sistêmico-funcional e lingüística de corpus. In: PAGANO, A.; MAGALHÃES, C.; ALVES, F. (Org.). Competência em tradução: cognição e discurso. Belo Horizonte: Editora da UFMG, 2005. 
THIBAULT, P. J. An interview with Michael Halliday. In: STEELE, R.; THREADGOLD, T. (Ed.). Language Topics: Essays in Honour of Michael Halliday. Amsterdam: John Benjamins, 1987.

THOMPSON, G. Organising the message: the textual metafunction - theme. In: Introducing functional grammar. 2002. 